\title{
Motivating College Students: Evidence from 20 Years of Anonymous Student Evaluations
}

\author{
Steven B. Oppenheimer \\ Department of Biology and Center for Cancer and Developmental Biology, California State University, Northridge, U.S.A \\ Email address: \\ steven.oppenheimer@csun.edu \\ To cite this article: \\ Steven B. Oppenheimer. Motivating College Students: Evidence from 20 Years of Anonymous Student Evaluations. Higher Education \\ Research. Vol. 4, No. 2, 2019, pp. 42-45. doi: 10.11648/j.her.20190402.14
}

Received: May 12, 2019; Accepted: June 15, 2019; Published: June 26, 2019

\begin{abstract}
The career outcomes of hundreds of college students, mostly biology majors, mentored by U.S. Presidential Awardee (PAESMEM) Steven Oppenheimer, over a 47 year period, at California State University, Northridge, were tracked and recorded. The motivational strategies that putatively helped lead to these career outcomes were gleaned from 20 years of anonymous student evaluations. In addition, evidence is presented that the motivational strategies, in some cases, were a likely cause of student career success and not just correlated with it. The student evaluations suggest that boundless energy, enthusiasm, clarity and organization keep students excited and engaged, helping to motivate them to succeed. Motivation at the pre-college level is also discussed, as by the time students enter college their career choices are often already made. These programs helped win a U.S. Presidential Award, the highest U.S. Award for student mentoring.
\end{abstract}

Keywords: Motivational Strategies, US. Presidential Award, 20 Years of Anonymous Student Evaluations

\section{Introduction}

Steven Oppenheimer, received a U.S. Presidential Award for science student mentoring presented by President Obama at the White House [1-7]. This award is the highest U.S. award for science student mentoring. The award was primarily based on hundreds of documented distinguished career outcomes of Steve Oppenheimer's mentees, summarized by Herstein (2016) [1]. In this paper the specific student evaluations from 20 years of anonymous student comments are reviewed and the specific motivational strategies to help students succeed are summarized. These strategies are discussed in the context of global thoughts on motivation and how individual faculty motivation fits into other factors that keep students motivated and engaged [8-9]. The relationship between faculty motivational strategies as being causal versus being correlated with student success is discussed [8], as is motivation at the pre-college level, perhaps most important of all [10-11].

\section{Methods}

This paper gleans from about 20 years of required anonymous student evaluations of California State
University, Northridge biology professor Steven Oppenheimer, how the motivational approaches used affected the students in their own words. An abbreviated version of student evaluations can be found using Google (at Rate My Professor, Steven Oppenheimer, California State University Northridge). Most of the evaluations concern the upper division majors biology course Embryology, Biology 441, and some are about the lower division mixed majors, non-majors course Biology of Cancer, Biology 285. The actual 20 years of evaluations can be obtained by contacting steven.oppenheimer@csun.edu.

\section{Results and Discussion}

Motivational strategies from student evaluations.

While the quantitative evaluations were all at the top of a 5 point scale, they do not capture the flavor of the motivational strategies used. Some of the verbatim (some shortened) comments by the students over the 20 year period were as follows:

fun and interactive, offers research opportunities, passionate, inspirational, patient, motivating, clear, interesting, organized, treats students with respect, positive vibe, very approachable, easy to understand, cares about 
student success, straightforward, enjoys teaching, great sense of humor, understand more in other classes because of Dr. Oppenheimer's teaching, engages students, best professor ever, very clear, makes sure students understand, keeps us focused, I always enjoy coming to class, optimistic, very good communicator, excellent knowledge of the topic, definitely keeps us awake, intriguing and engaging, encourages questions, love his energy, the best class I ever had.

Some additional flavor of Steve Oppenheimer's philosophy of motivation was presented at the White House on Jan 6, 2010, when Oppenheimer was recognized by President Obama, NSF and the White House. The official White House/NSF brochure produced for the Presidential Award ceremony said of Oppenheimer: Putting into practice his belief that laboratory research experiences should be available to all interested students, he has developed an open door model that encourages students of all economic strata and ethnic groups to participate in his research. His record has proven true his often-stated expectation that any interested student can succeed in scientific research and can go far into the professional career ranks of science, including the Ph.D. and M.D. (a copy of this NSF/White House produced brochure can be obtained by contacting steven.oppenheimer@csun.edu).

Specific example of motivation putatively causing a specific career outcome.

The documented career success of so many hundreds of students mentored by Steve Oppenheimer played a key role in the U.S. Presidential Award as noted by the NSF Presidential Award peer review panel. The evidence presented is mostly correlation and does not provide any clarity on causal relationships. Serendipity has provided an example that gets more into possible causal relationships. This is about one student, of several, who made a donation to the university of student scholarship (s) in honor of Steve Oppenheimer. But in this case an astute reporter unraveled how motivation by Steve Oppenheimer led to her acceptance to Stanford University Medical School (and is now a co-director of emergency medicine at a large Los Angeles Hospital). Here is some of her story in her own words [8]. Her daughters asked, Mom, how did you become a doctor...In unraveling 20 years worth of layers she remembered Dr. Oppenheimer. She decided to make the gift to the university because she said Dr. Oppenheimer changed the trajectory of her life. It began when she took Oppenheimer's undergraduate embryology course Biology 441, the main subject of the anonymous student evaluations presented above. After that she worked in Oppenheimer's research lab. [7]. She said being in Dr. O's lab as an undergraduate was awesome. He encouraged every person that walked into the lab to do everything they wanted to do and helped them find ways to do it. She said Oppenheimer's encouragement made a profound impact on her life...He gave me the confidence to apply to medical school. He gave me the study skills, research skills and knowledge base to succeed. He said you're the best and you can become a doctor if you want to be one. He gave me the confidence to apply to medical school He changed the trajectory of my life. See the great article about this student that is provided here (Camacho, 2018) [8]. It's hard to assign causality to motivational strategies. But this story comes close. Here follows the Camacho (2018) [8] article. It is important to present it in its entirety to truly provide the details of how Steve Oppenheimer's motivation does the job.

In emergency rooms across the United States, nurses, doctors and hospital staff know never to say the "Q" word. The dreaded word isn't "question," "quarrel" or "quick" it's "quiet."

It's a rare time for an emergency room when the phones aren't ringing and patients aren't arriving, but that can all change in minutes, according to an ER superstition. As soon as someone remarks, "It's going to be a quiet night, isn't it?," everything changes: Ambulances flood the ER with patients until it's bursting.

As a doctor of emergency medicine and Co-Medical Director of Burbank Emergency Medical Group at Providence Saint Joseph Medical Center in Burbank, it's a situation that Celina Barba-Simic '92 (Cell and Molecular Biology) knows all too well.

Barba-Simic's only access to medical care as a child was the busy county emergency department, which "normalized" long waits, chaos and language barriers for the alumna. When she decided to pursue a career in medicine, emergency medicine was the only specialty she considered.

"Attending to people at times of crisis represents the greatest privilege of medicine," Barba-Simic said. "I am most grateful to be able to alleviate anxiety and have an impact on patients' acute medical needs..."

Barba-Simic always knew she wanted to work in medicine, but she never imagined that learning not to say the "Q" word would be such a valuable lesson - nor did she know that she would be drawn to the fast-paced world of emergency medicine.

Her path became clearer when she took a human embryology course with - and later joined the Center for Cancer and Developmental Biology of - esteemed biology professor Steven Oppenheimer at California State University, Northridge.

His influence on her was so profound that Barba-Simic recently made a gift to the CSUN College of Science and Mathematics to create the Dr. Celina Barba-Simic Biology Scholarship in Honor of Dr. Steven Oppenheimer.

The annual scholarship will provide one award for an undergraduate student with demonstrated financial need who is also conducting laboratory research in the College of Science and Mathematics' Department of Biology.

She decided to make the gift, she said, after her daughters asked her a tough question: "Mom, how did you become a doctor?"

"One day they just asked me how I did it," Barba-Simic said. "And I really tried to unravel all of those layers of skills and education." 
In unraveling 20 years' worth of layers, Barba-Simic remembered her inspiring professor of human embryology.

"Dr. Oppenheimer at CSUN gave me the comfortable, accessible starting point where I could really start building those skills and seeing that there are possibilities," she said. "He was absolutely essential."

\section{Her Time at CSUN}

Oppenheimer, who has mentored thousands of students during his 40-year tenure as a CSUN professor, said that Barba-Simic stood out when she was an undergraduate.

"Celina had sparkle, spark and enthusiasm seldom seen in students," Oppenheimer said. "The combination of her enthusiasm and my enthusiasm made for great success. Celina's spark was inspirational."

After getting to know the professor - now emeritus Barba-Simic joined the famed Oppenheimer lab. "Being in Dr. O's lab was awesome. He made it approachable and hands-on," she said. "Everything was accessible. $\mathrm{He}$ encouraged every person that walked in there to do everything they wanted to do and helped them find ways to do it."

In the lab, Barba-Simic helped research cell surface carbohydrates in adhesion and migration, to explore how cells' surface sugar-containing receptor sites change during development. The study aimed to determine the function of those carbohydrates in order to find causes of cancer-cell spread.

Barba-Simic said the professor's encouragement made a profound impact on her life.

"You walk in and he's saying, 'You're wonderful and you're the best!' It was life-changing, his teaching and his classes," she said. "It prepared me for medical school. I knew I had the study skills, the research skills and the knowledge base [to succeed]."

Although she learned many things from him, the most important idea the professor instilled in Barba-Simic was this You can be a doctor if you want to be.

"I reflected on the impact my time in Dr. Oppenheimer's lab had on my career," Barba-Simic said. "He gave me the confidence to apply to [medical school]. Dr. Oppenheimer changed the trajectory of my life."

\section{Overcoming Barriers}

A first-generation college student born in Mexico and raised in Pacoima, Barba-Simic and her parents came to the U.S. when she was three months old. She started working at the age of 15 and had two jobs by the time she was 16 . She used her wages to pay for essentials.

"When I was graduating high school, I brought the UC application to my mom and was like, 'How many of these boxes can I check off?' I think the applications were around $\$ 50$ each," Barba-Simic said. "And she said, 'Oh, honey, we can't afford that and you can't move away from home."”

Financial and cultural constraints led Barba-Simic to CSUN, where she initially enrolled as a physical therapy major. Once at CSUN, she encountered cultural barriers to her education from well-meaning family and friends.

"I knew I wanted to be a physician, but everybody told me,
'Oh, don't be a doctor. It takes too long and you're going to get married anyway,"” Barba-Simic said.

Despite the financial and cultural barriers, Barba-Simic paved her way to medical school by volunteering at the Veterans Affairs Sepulveda Ambulatory Care Center, just a few miles east of campus, doing research and participating in on-campus organizations such as Chicanos for Community Medicine.

At the end of her undergraduate time at CSUN, BarbaSimic received multiple awards including Graduating Student of the Year Award from the Department of Biology and the Minority Achievers in Science Student of the Year Award. She also received multiple scholarships, fostering her appreciation of the financial needs of low-income students and later inspiring her to make a gift to aid those in need.

Barba-Simic made the gift to her alma mater in hopes of supporting "CSUN students that share similar challenges and career goals."

As an involved undergraduate, Barba-Simic applied for and later received — the National Institutes of Health Minorities Access to Energy Related Careers grant, with Oppenheimer's encouragement, she said.

"The grant paid for two years [of undergrad], so I was able to stop working," she said. "In the summer, the grant allowed me to conduct research in a Department of Energy lab and use the skills that Dr. O taught me.

"I was lucky to be at Lawrence-Berkeley National Laboratory working under Dr. Levy ... where my job was to irradiate mice brain cell cultures, subjecting them to different levels of radiation and testing Bragg peaks using the linear accelerator. This was but a small part of the research that Dr. Levy used to perfect proton therapy for high-precision treatment of brain tumors and vascular malformations," she added.

\section{Perseverance}

After graduating from Stanford Medical School, BarbaSimic completed a three-year emergency medicine residency at Harbor-UCLA Medical Center, where she started work as early as 4 a.m. and ended as late as 7 p.m. - the following day. This meant Barba-Simic often worked 38-hour shifts and 120-hour weeks.

On top of extremely long hours, in the first three months of her residency, Barba-Simic became pregnant with her first child. She went to her fellow residents and asked to switch schedules around so that her vacation was at the end of her first year.

"Once I switched it all, I went to my residency director and said, 'I have a plan.' I did not miss a day," Barba-Simic said. "I actually went into labor my last day. I guess you're so used to, as a minority, working harder and trying to prove yourself that it's just part of you."

At the start of her residency, she was one of two women in a class of 12 , but she didn't let that disparity discourage her from accomplishing her goals and realizing her full potential.

"You make it happen," she said. "I'm kind of tough - I think that's the Pacoima in me."

The influence that Oppenheimer had on her was invaluable, 
as was the education and training he provided. "Dr. Oppenheimer changed my life by believing in me and providing the opportunity," she said.

Also mentioned in the student evaluation comments, was one that caught the eye of a NSF panel reviewer on the Presidential Award panel: He calls his students professors and doctors. I'm going to try doing that. It's a motivational gimmick that is both inspirational and transformative that reflects his boundless enthusiasm. (NSF Proposal 0731633, March 6, 2007) [1-6].

A survey of both students and their instructors indicated that the students (49\%) and instructors $(46 \%)$ selected career goals as the primary reason for keeping college students motivated to succeed. Future earning goals came in second. GPA and advanced degrees were also motivational factors (Strang, 2015). [9] In many cases, therefore, motivation by individual instructors may not be the primary overall motivator. But in some cases it likely is (Camacho, 2018) [8].

\section{Before College.}

By the time students enter college their minds are often made up with respect to career choices. It is perhaps more important to motivate youngsters before college towards interest in science careers. Many pre-college science experiences such as science fairs focus on recognizing high achievers and the thousands of average students are not encouraged to explore possible science careers. Part of the U.S. Presidential Award mentioned earlier was for accomplishments in 23 years of publishing a worldwide web open access Library of Congress listed pre-college science abstracts research journal and organizing annual pre-college science research symposia. All students, not just the high achievers are recognized in these programs. The reference list includes links to all 23 annual volumes of the pre-college research journal that are downloadable free-of-charge to anyone in the world. [10]. The journal recently won the $4^{\text {th }}$ annual Oviatt Open Access Award [11]

\section{Conclusions}

The student evaluation comments, over a 20 year period, suggest that boundless energy, enthusiasm, clarity and organization keep students excited and engaged, helping to motivate them to succeed. This conclusion is based on 20 years of anonymous student evaluations and recognition by the White House and the National Science Foundation [1-9]. The pre-college results are based on decades of motivational strategies for all students, not just the high achievers [10-11].

\section{Acknowledgements}

The author thanks California State University, Northridge, that was recently recognized by Nature magazine as a Rising Star in Research in North America, for 47 years of outstanding support. Various accounts such as CSUN Foundation and Corporation accounts (E1266) helped support these programs.

\section{References}

[1] Herstein, O., 2016, Steven Oppenheimer, CSUN Magazine, no. 67, p. 20, Fall 2016.

[2] NSF Proposal 0731633, March 6, 2007, Individual-Steven Oppenheimer Mentor, Researcher, Teacher.

[3] National Science Foundation Excellence Awards in Science and Engineering Program: Presidential Awards for Excellence in Science, Mathematics and Engineering Mentoring (EASE: PAESMEM). Solicitation 16-534. 2019. The U.S. Presidential Award is the highest U.S. Award for student mentoring in science (https://paesmem.net).

[4] OSTP and NSF to honor 140 individuals and organizations with highest US award for teachers and mentors. News Release 18-043, June 25, 2018.

[5] Presidential Awards for Excellence in Science, Mathematics and Engineering Mentoring, NSF Home Page, 2019.

[6] NSF Proposal 07316333, March 6, 2007, Individual-Steven Oppenheimer Mentor, Researcher, Teacher.

[7] Oppenheimer, S. B., 2015, Undergraduate Research in Action, Nature 519, p. 158, March 12, 2015.

[8] Camacho, N. L., 2018, ER Doctor's Gift Honors Biology Professor for Changing the Trajectory of Her Life, CSUN Magazine, May 30, 2018 and CSUN Weekly vol. 5, Ed. 42, June 12, 2018.

[9] Strang, T., 2015, What Keeps College Students Motivated?, Engagement and Motivation, Student Engagement, www.Cengage.com., Jan 14, 2015.

[10] http://scholarworks.csun.edu/handle/10211.3/125029 This collection contains volumes I - XXIII of The New Journal of Student Research Abstracts. Published in conjunction with CSUN and several publishing partners, and edited by CSUN biology faculty member Steven Oppenheimer, the journal contains abstracts of K-12 student science experiments. 23 volumes (1995-2018).

[11] Lewis, T., 2018, Oviatt Library Hosts Fourth Annual Open Access Symposium, https://csunshinetoday.csun.edu/...oviattlibrary-hosts-fourth-annual-open-access-sym...Jan 24, 2018. 